\title{
Estrutura dos grânulos de amido e sua relação com propriedades físico-químicas
}

\author{
Starch granules structure and its regards with physicochemical properties
}

\author{
Cristiane Casagrande Denardin ${ }^{\mathrm{I}}$ Leila Picolli da Silva ${ }^{\mathrm{II}}$
}

\section{- REVISÃO BIBLIOGRÁFICA -}

\section{RESUMO}

Devido aos escassos trabalhos brasileiros sobre a estrutura dos grânulos de amido, o objetivo desta revisão foi demonstrar os avanços atuais na elucidação da arquitetura e da estrutura química desse polímero. Muitas pesquisas sobre a avaliação da relação existente entre a estrutura molecular do amido e seu comportamento em algumas propriedades físicoquímicas sugerem que diversas características estruturais, tais como teor de amilose, distribuição de comprimento das cadeias de amilopectina e grau de cristalinidade no grânulo, estejam intimamente relacionadas a eventos associados à gelatinização e retrogradação, como inchamento do grânulo, lixiviação de amilose e/ou amilopectina, perda da estrutura radial (birrefringência), supra-molecular (cristalinidade) e molecular e recristalização. O foco principal desta revisão foi a compilação de estudos a fim de obter melhor entendimento da estrutura e das características dos componentes do amido e sua relação com propriedades físico-químicas, principalmente no que diz respeito à gelatinização e retrogradação, as quais apresentam grande importância nutricional e tecnológica.

Palavras-chave: amilose, amilopectina, gelatinização, retrogradação.

\section{ABSTRACT}

Due to poor Brazilians work on the structure of starch granules, the purpose of this review was to demonstrate the advances in current understanding of architecture and chemical structure of this polymer. Many studies evaluating the relationship between the molecular structure of starch and its behavior in some physicochemical properties, suggest that several structural features, such as amylose content, amylopectin chain length distribution and the degree of crystallinity in the granule, are closely related to the events associated with gelatinization and retrogradation as starch granule swelling, amylose and/or amylopectin leaching, loss of radial structure (birefringence), supra-molecular (crystallinity) and molecular order, and recrystallization. The main focus of this review was to make a compiler of studies in order to gain better understanding of the granule structure and characteristics of starch components and physicochemical properties (gelatinization and retrogradation) that could play a significant role in improving the quality of different food products.

Key words: amylose, amylopectin, gelatinization, retrogradation.

\section{INTRODUÇÃO}

O amido encontra-se amplamente distribuído em diversas espécies vegetais como um carboidrato de reserva, sendo abundante em grãos de cereais (40\% a $90 \%$ do peso seco), leguminosas (30\% a $50 \%$ do peso seco), tubérculos (65\% a $85 \%$ do peso seco) e frutas imaturas ou verdes (40\% a $70 \%$ do peso seco) (LAJOLO \& MENEZES, 2006). Ele é também a fonte mais importante de carboidratos na alimentação humana, representando $80 \%$ a $90 \%$ de todos os polissacarídeos da dieta (WHO/FAO, 1998). Porém, sabe-se que a taxa

INúcleo Integrado de Desenvolvimento em Análises Laboratoriais (NIDAL), Departamento de Tecnologia e Ciência de Alimentos (DTCA), Centro de Ciências Rurais (CCR), Universidade Federal de Santa Maria (UFSM), 97105-900, Santa Maria, RS, Brasil. Email: cristiane_denardin@yahoo.com.br. Autor para correspondência.

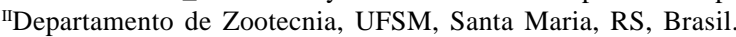


e a extensão da digestão do amido no organismo humano podem ser influenciadas por diversos fatores, incluindo a variação na proporção amilose:amilopectina, o processamento dos alimentos e as propriedades físico-químicas, como gelatinização e retrogradação (BJÖRCK et al., 1994). Além disso, o amido é o principal responsável pelas propriedades tecnológicas que caracterizam grande parte dos produtos processados, uma vez que contribui para diversas propriedades de textura em alimentos, possuindo aplicações industriais como espessante, estabilizador de colóides, agente gelificante e de volume, adesivo, na retenção de água, dentre outros (SINGH et al., 2003).

Sendo formado nos plastídeos das plantas superiores, o amido é sintetizado nas folhas, onde serve como carboidrato de reserva temporário, acumulandose nos cloroplastos durante o dia e servindo como fonte principal para a síntese de sacarose citosólica durante a noite. Essa sacarose é então transportada para os órgãos de armazenamento das plantas, como sementes, frutas, tubérculos e raízes (VANDEPUTTE \& DELCOUR, 2004; TESTER et al., 2004).

Estruturalmente, o amido é um homopolissacarídeo composto por cadeias de amilose e amilopectina. A amilose é formada por unidades de glicose unidas por ligações glicosídicas $\alpha-1,4$, originando uma cadeia linear. Já a amilopectina é formada por unidades de glicose unidas em $\alpha$-1,4 e $\alpha$ 1,6, formando uma estrutura ramificada. As proporções em que essas estruturas aparecem diferem em relação às fontes botânicas, variedades de uma mesma espécie e, mesmo numa mesma variedade, de acordo com o grau de maturação da planta (ELIASSON, 2004; TESTER et al., 2004).

Atualmente, diversas pesquisas sobre a avaliação da relação existente entre a estrutura molecular do amido e seu comportamento em algumas propriedades físico-químicas sugerem que diversas características estruturais, como teor de amilose, distribuição de comprimento das cadeias de amilopectina e grau de cristalinidade no grânulo, poderiam estar intimamente relacionadas aos eventos associados com a gelatinização e retrogradação, tais como inchamento do grânulo, lixiviação de amilose e/ ou amilopectina, perda da estrutura radial (birrefringência), supra-molecular (cristalinidade) e molecular e recristalização. Com isso, o presente artigo de revisão tem por objetivo reunir tais estudos visando um maior entendimento da estrutura e das características dos componentes do amido e sua relação com propriedades físico-químicas de grande importância nutricional e tecnológica.
Formas moleculares

Amilose

A amilose é um polímero essencialmente linear, formado por unidades de $\alpha$-D-glicopiranose ligadas em $\alpha-(1,4)$, com poucas ligações $\alpha-(1,6)$ (entre 0,1\% e 2,2\%), conforme CURÁ et al., 1995; Ball (1996) apud OATES, 1997; OATES, 1997; BULEÓN et al., 1998 (Figura 1A). Essa molécula possui número médio de grau de polimerização (DP) de 500-5000 unidades de resíduos de glicose (OATES, 1997), com comprimentos médios de cadeia (CL) de 250-670 e limite de $\beta$-amilose entre 73\% e 95\%, o qual está relacionado às proporções lineares e ramificadas da molécula, à quantidade e à localização das ramificações, bem como ao comprimento da cadeia (ELIASSON, 1996; BULEÓN et al., 1998; VANDEPUTTE \& DELCOUR, 2004).

O peso molecular é da ordem de 250.000 Daltons (1500 unidades de glicose), mas varia muito entre as espécies de plantas e dentro da mesma espécie, dependendo do grau de maturação. Moléculas de amilose de cereais são geralmente menores do que aquelas de outras origens (ex. tubérculos e leguminosas).

Níveis entre $15 \%$ e $25 \%$ de amilose são típicos na maioria dos grãos, contudo, alguns cereais denominados cerosos (waxy), como milho, arroz e cevada, são virtualmente livres de amilose, enquanto mutantes com altos níveis de amilose também são conhecidos. Os mutantes amilose extender (ae) do milho apresentam conteúdos de amilose que variam de $50 \%$ a $85 \%$. Já mutantes ae do arroz apresentam conteúdos de amilose que variam de $35 \%$ a $40 \%$ (VANDEPUTTE \& DELCOUR, 2004).

A amilose pode estar presente sob a forma de complexos amilose-lipídios (LAM - lipid-amylose complexes) ou de amilose livre (FAM - free amylose). Os LAM, embora detectados no amido nativo, possivelmente sejam formados em maior extensão durante o tratamento hidrotérmico ou a gelatinização (ELIASSON, 1996; ELIASSON, 2004; TESTER et al., 2004; VANDEPUTTE \& DELCOUR, 2004).

Muitas propriedades da amilose podem ser explicadas pela sua habilidade em formar diferentes estruturas moleculares. A maioria das metodologias preconizadas para determinação desse tipo de amido baseia-se no fato de que, em soluções aquosas neutras, a estrutura normal de espiral possui a capacidade de interagir com iodo, produzindo complexo de inclusão helicoidal com aproximadamente seis moléculas de amilose por giro, no qual o iodo se encontra na cavidade central da hélice.

Além disso, mudanças moleculares tornam possível a formação de complexos com moléculas de lipídios nas regiões superficiais do grânulo, o que inibe a degradação do amido por enzimas como fosforilase, 


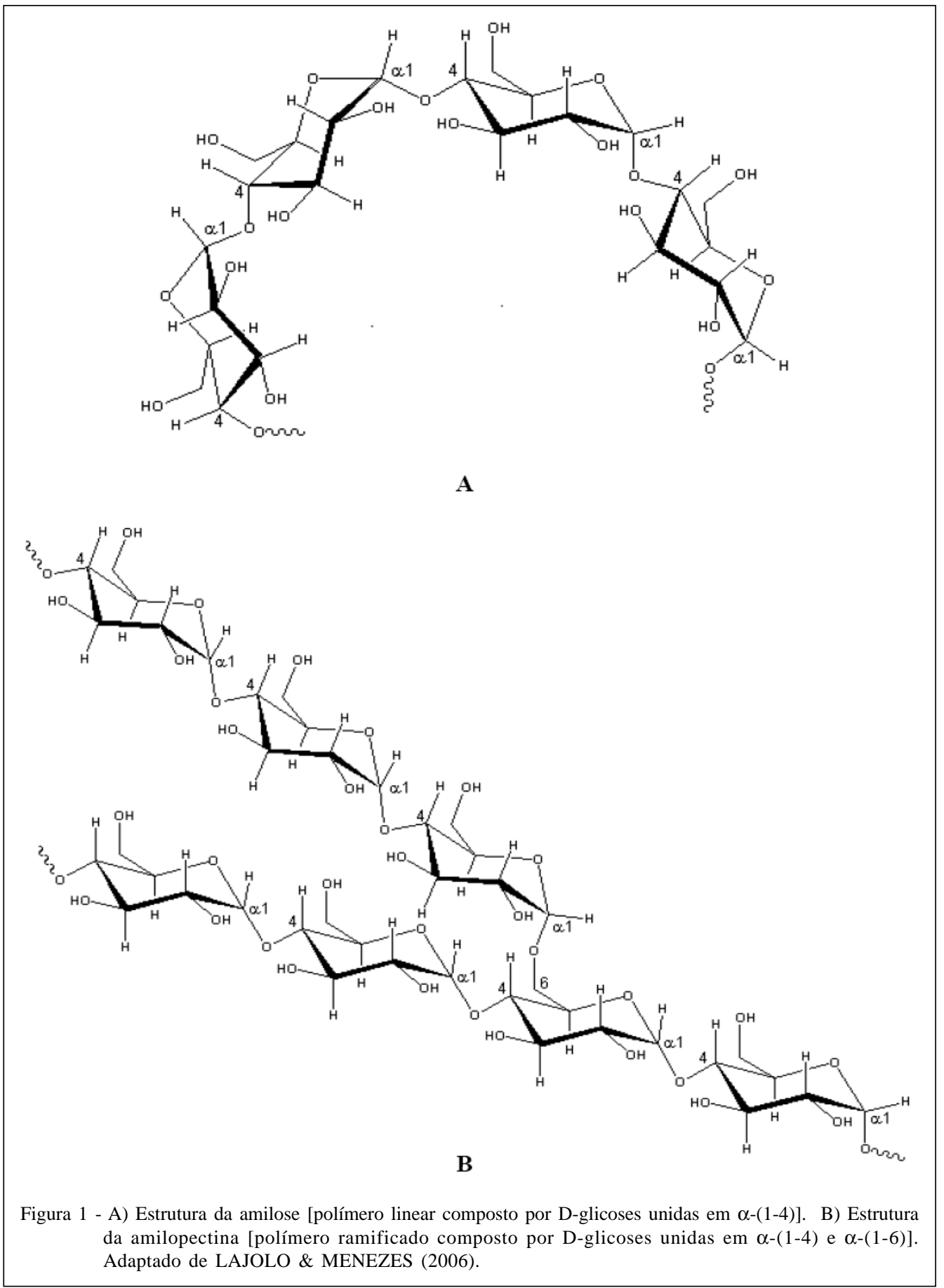

$\alpha$-amilase e $\beta$-amilase. Outros complexos de inclusão helicoidal que podem ser formados com a amilose incluem alguns álcoois e ácidos orgânicos (ELIASSON, 1996; ELIASSON, 2004).

Amilopectina

A amilopectina é o componente ramificado do amido. Ela é formada por cadeias de resíduos de $\alpha$ -
D-glicopiranose (entre 17 e 25 unidades) unidos em $\alpha$ $(1,4)$, sendo fortemente ramificada, com $4 \%$ a $6 \%$ das ligações em $\alpha-(1,6)$ (Figura 1B). O peso molecular da amilopectina varia entre 50 e $500 \times 10^{6}$ Daltons (VANDEPUTTE \& DELCOUR, 2004; LAJOLO \& MENEZES, 2006).

Segundo VANDEPUTTE \& DELCOUR (2004), a amilopectina apresenta um DP de 4700 a 12800

Ciência Rural, v.39, n.3, mai-jun, 2009. 
unidades de resíduos de glicose, valores de CL de 17 a 24 e limite de $\beta$-amilose de $55 \%$ a $60 \%$. As cadeias individuais podem variar entre 10 e 100 unidades de glicose.

Segundo BULEÓN et al. (1998) e LAJOLO \& MENEZES (2006), a amilopectina é digestivamente degradada pela ação da $\beta$-amilase nas uniões $\alpha-(1-4)$, produzindo dextrinas $\beta$-limite (cadeias residuais que contém os pontos de ramificação) e, posteriormente, por ação das enzimas pululanase e isoamilase que atuam nas ligações $\alpha-(1-6)$, produzindo maltose.

As cadeias de amilopectina estão organizadas de maneiras diferentes, sugerindo uma classificação de cadeias A, B e C (Figura 2A). O tipo A é composto por uma cadeia não-redutora de glicoses unidas por ligações $\alpha-(1,4)$ sem ramificações, sendo unida a uma cadeia tipo B por meio de ligações $\alpha-(1,6)$. As cadeias do tipo B são compostas por glicoses ligadas em $\alpha$ - $(1,4)$ e $\alpha-(1,6)$, contendo uma ou várias cadeias tipo A e podem conter cadeias tipo B unidas por meio de um grupo hidroxila primário. A cadeia C é única em uma molécula de amilopectina, sendo composta por ligações $\alpha$ - $(1,4)$ e $\alpha-(1,6)$, com grupamento terminal redutor (ELIASSON, 1996; ELIASSON, 2004; VANDEPUTTE \& DELCOUR, 2004; LAJOLO \& MENEZES, 2006).

Cada cadeia pode ser especificamente classificada de acordo com seu comprimento (CL) e, conseqüentemente, sua disposição dentro dos grânulos (HIZUKURI, 1985; HIZUKURI, 1986). Segundo TESTER et al. (2004) e VANDEPUTTE \& DELCOUR (2004), a amilopectina tem uma distribuição polimodal com cadeias A(CL 12-16) e B, isto é, cadeias $\mathrm{B}_{1}$ (CL 20-24), $\mathrm{B}_{2}$ (CL 42-48), $\mathrm{B}_{3}$ (CL 69-75) e $\mathrm{B}_{4}$ (CL 104140 ). As cadeias $A$ e $B_{1}$ formam cachos simples, são mais externas e organizadas em duplas hélices, enquanto $B_{2}, B_{3}$ e $B_{4}$ se estendem em dois, três e mais de quatro cachos. As cadeias $C$ são muito semelhantes entre as fontes botânicas com variações de tamanhos entre 10 e 130 unidades de glicose, a maioria tendo por volta de 40 unidades.

A amilopectina é, estrutural e funcionalmente, a mais importante das duas frações, pois sozinha é suficiente para formar o grânulo, como ocorre em mutantes que são desprovidos de amilose. Quanto à amilose, sua localização exata dentro do grânulo ainda é uma tarefa difícil. Acredita-se que ela esteja localizada entre as cadeias da amilopectina e aleatoriamente entremeada entre as regiões amorfas e cristalinas. As moléculas de amilose maiores estão concentradas no centro do grânulo e, provavelmente, participam das duplas hélices com a amilopectina, enquanto as moléculas menores presentes na periferia podem ser lixiviadas para fora do grânulo. Apesar de seu limitado papel na formação de cristais, a amilose pode influenciar a organização das duplas hélices, interferindo na densidade de empacotamento das cadeias de amilopectina (OATES, 1997; TESTER et al., 2004). Além disso, estudos recentes (BAKER at al., 2001; KUAKPETOON \& WANG, 2007) sugerem que parte da amilose pode cristalizar-se juntamente com a amilopectina, formando lamelas cristalinas. Porém, a organização exata desses componentes dentro do grânulo ainda não está totalmente esclarecida.

\section{Material intermediário}

LANSKY et al. (1949) apud ELIASSON (2004) propuseram a existência de um terceiro componente no amido de milho normal, chamado de material intermediário (MI), com propriedades diferentes da amilose e da amilopectina. Esse componente pode também apresentar papel importante na determinação das propriedades funcionais do amido. A presença de um grande número de cadeias ramificadas curtas nesse componente pode contribuir para a menor cristalinidade granular, a temperatura de gelatinização, a mudança na entalpia, a viscosidade e o grau de retrogradação e o maior grau de digestibilidade pelas enzimas que promovem a hidrólise enzimática. Por outro lado, moléculas ramificadas que apresentam longos comprimentos de cadeias e menores graus de ramificação podem contribuir para a maior cristalinidade, a temperatura de gelatinização, o grau de retrogradação, a viscosidade e a firmeza de gel (VANDEPUTTE et al., 2003a). Com base em estudos de afinidades por iodo, esses pesquisadores sugeriram que $5 \%$ a $7 \%$ do amido de milho normal consiste de material intermediário entre as frações estritamente lineares e altamente ramificadas (ELIASSON, 2004).

No entanto, o conceito de material intermediário ainda é obscuro devido a dificuldades no seu isolamento e na purificação, sendo que o principal critério para classificação ainda é o grau de ramificação e o peso molecular (ELIASSON, 1996). Alguns pesquisadores consideram as amiloses ramificadas, com 20 ou mais pontos de ramificação em média, como sendo intermediárias (WANG \& WHITE, 1994; ELIASSON, 1996; ELIASSON, 2004). Contudo, existem aqueles que não reconhecem essa amilose ramificada como intermediário, uma vez que suas propriedades são muito semelhantes àquelas da amilose tradicional (ASAOKA et al., 1986; BULÉON et al., 1998). Essa controvérsia ocorre devido às dificuldades ainda enfrentadas na caracterização precisa das cadeias da amilose e da amilopectina, uma vez que os limites de suas propriedades ainda são muito vagos e confusos. 


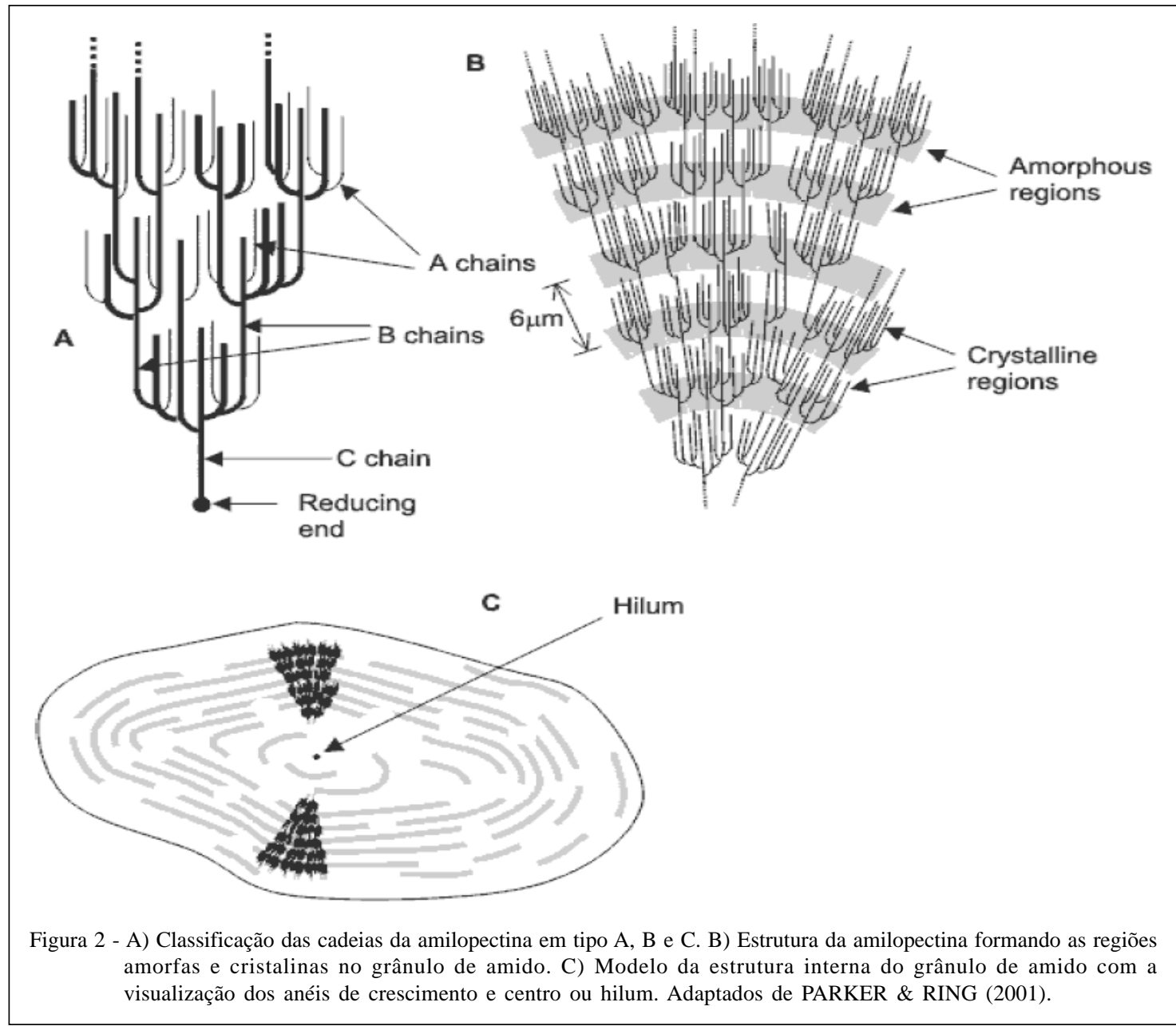

Estrutura granular

Tamanho, forma e superfície

O amido encontra-se nas plantas sob a forma de grânulos. Em cereais como trigo, milho, cevada, centeio e sorgo, os grânulos podem ser classificados como simples, quando cada plastídeo contém um grânulo, ou compostos (arroz e aveia), quando muitos grânulos estão dentro de cada amiloplasto (LINDEBOOM et al., 2004; LAJOLO \& MENEZES, 2006).

Segundo VANDEPUTTE \& DELCOUR (2004) e TESTER et al. (2004), a forma (redondo, oval, poliédrico), o tamanho de partícula (2 a $100 \mu \mathrm{m})$ e a distribuição de tamanho da partícula (unimodal, bimodal, trimodal) dos grânulos são características da origem botânica. Quanto à distribuição de tamanho de partícula, a maioria dos cereais apresenta distribuição bimodal, sendo compostos por grânulos grandes (10 a $35 \mu \mathrm{m})$ e lenticulares denominados grânulos A e grânulos pequenos (diâmetro entre 1 e $10 \mu \mathrm{m}$ ) e esféricos denominados de grânulos B (ELIASSON, 1996; ELIASSON, 2004; TESTER et al., 2004).
Segundo OATES (1997) e BULEÓN et al. (1998), a superfície dos grânulos é plana e sem traços marcantes, exceto por algumas estrias e fissuras visíveis em alguns grânulos através de microscopia eletrônica de varredura (SEM - scanning electron microscopy). A base para os modelos atuais foi proposta por Lineback (1984) apud OATES (1997), descrita como uma “bola de bilhar peluda”, em que a superfície do grânulo não é lisa, mas caracterizada por cadeias projetadas para fora. Posteriormente, STARK \& LYNN (1992) descreveram um grânulo cuja superfície é caracterizada pelos terminais das cadeias de amilose e pelas ramificações da amilopectina, que seriam responsáveis pelo início da próxima camada de crescimento dos grânulos. Atualmente, a morfologia e a visualização de componentes secundários da superfície de alguns grânulos de amido têm sido realizadas por meio de microscopia de força atômica (AFM - atomic force microscopy) (BULEÓN et al., 1998).

Quanto à permeabilidade, a superfície do grânulo é relativamente impermeável a moléculas

Ciência Rural, v.39, n.3, mai-jun, 2009. 
grandes, como amilases, devido ao compacto empacotamento das cadeias de amilopectina. Segundo French (1984) apud ELIASSON (2004), a porosidade dos grânulos de amido à água e a pequenas moléculas solúveis ocorre devido à expansão reversível das regiões amorfas, que penetram por todo o grânulo durante a hidratação, formando uma fase contínua de gel. No entanto, a entrada de enzimas hidrolizantes e outras moléculas grandes para o interior dos grânulos é restrita e somente possível através de poros ou canais. Esses poros, na superfície de alguns grânulos, são orifícios ou canais que penetram em uma direção radial ao longo do grânulo. Estudos de SEM sugerem orifícios com diâmetros entre 0,1 e $0,3 \mu \mathrm{m}$, enquanto canais interiores teriam entre 0,07 e 0,1 $\mu \mathrm{m}$ (ELIASSON, 1996; ELIASSON, 2004). Porém, mais estudos devem ser realizados para comprovar a existência desses poros e canais em todas as fontes de amido, pois estudo recente realizado com amido de trigo nativo utilizando SEM não apresentou nenhuma evidência destes na superfície dos grânulos (LAN et al., 2008). Além disso, as técnicas atualmente disponíveis para a visualização da superfície e do interior dos grânulos de menor diâmetro (como arroz) ainda precisam ser melhoradas.

\section{Estrutura interna e cristalinidade}

Em solução aquosa, o grânulo de amido é birrefringente quando visto microscopicamente sob luz polarizada. A refração pelas suas regiões cristalinas resulta no modelo típico de “Cruz de Malta”, o que caracteriza a orientação radial das macromoléculas. O centro ou "hilum", encontrado no centro da cruz, é considerado o ponto original de crescimento do grânulo. Essa propriedade de birrefringência é devida ao alto grau de orientação molecular interna, não tendo qualquer relação com a forma cristalina em particular (ELIASSON, 2004; LAJOLO \& MENEZES, 2006).

Segundo OATES (1997), uma característica estrutural que tem sido identificada por meio de hidrólise enzimática controlada são os chamados anéis de crescimento. Internamente, o material do grânulo está presente na forma de anéis concêntricos, conhecidos como anéis de crescimento (Figura 2C). Essas estruturas são visíveis sob microscópio óptico em grânulos grandes (batata e trigo), mas são raramente vistas nos pequenos (cevada e arroz). A existência de anéis de crescimento sugere que o amido seja depositado num ritmo diário, e que o material recémsintetizado esteja depositado na superfície, fazendo com que os grânulos aumentem seu tamanho. Um modelo para esse desenvolvimento sugere que a primeira camada de crescimento esteja no centro (hilum), que contém grande proporção de terminais redutores das moléculas de amido e é normalmente menos organizado que o resto do grânulo. Os terminais-não redutores da amilose e amilopectina irradiam para a superfície, permitindo a adição de mais resíduos de glicose para aumentar as cadeias de amilopectina (BAKER et al., 2001).

Os anéis de crescimento são organizados em regiões cristalinas e amorfas alternadas, motivo pelo qual é freqüentemente descrito como um polímero semicristalino ou parcialmente cristalino. A fusão desses cristais e o rompimento dessa estrutura organizada formam a base para a gelatinização (ELIASSON, 1996). A região cristalina é constituída pelas duplas hélices das cadeias paralelas A e B da amilopectina, sendo mais compacta, enquanto que a região amorfa, menos ordenada, contém os pontos de ramificação das cadeias laterais da amilopectina e possivelmente alguma amilose (Figura 2B) (ELIASSON, 1996; OATES, 1997; ELIASSON, 2004).

Os grânulos de amido nativos contêm entre $15 \%$ e $45 \%$ de material cristalino com modelos de difração de raios-X, que correspondem a duas poliformas (A ou B) ou a uma forma intermediária (C), as quais têm sua classificação baseada em variações no conteúdo de água e na configuração de empacotamento de duplas hélices (IMBERTY et al., 1991).

A cristalinidade tipo A ocorre na maioria dos cereais (milho, arroz, trigo, aveia) e é descrita como uma unidade celular monocíclica altamente condensada e cristalina, onde 12 resíduos de glicose de duas cadeias no sentido anti-horário abrigam quatro moléculas de água entre as hélices. A estrutura de padrão tipo B (tubérculos, arroz com alto teor de amilose e amido retrogradado) é mais claramente definida, sendo composta por uma unidade básica de cadeias que são empacotadas em um arranjo hexagonal, onde a unidade celular tem duas duplas hélices no sentido anti-horário, alinhadas e arranjadas em paralelo. Essa estrutura contém 36 moléculas de água (27\%) para cada 12 resíduos de glicose. A metade dessa água é fortemente ligada às duplas hélices, e a outra metade é concentrada em um eixo em parafuso (OATES, 1997; ELIASSON, 2004). Além de serem considerados mais ricos em amilose, esses tipos de amido apresentam formatos e tamanhos semelhantes e são resistentes a hidrólise, tanto enzimática quanto ácida (LAJOLO \& MENEZES, 1996). Certas raízes e sementes (ervilha lisa e fava) apresentam uma estrutura intermediária entre os modelos A e B, a qual é denominada de padrão C e é subclassificada em $\mathrm{Ca}, \mathrm{Cb}$ e $\mathrm{Cc}$, de acordo com a semelhança com os padrões A e B ou entre os dois tipos, respectivamente (ELIASSON, 1996; ELIASSON, 2004). 
Segundo LI et al. (2004), a maior suscetibilidade dos amidos com cristalinidade do tipo A à hidrólise ocorre devido à presença de poros superficiais que podem ser alargados pela ação das enzimas, facilitando sua ação no interior do grânulo. Outra possível explicação para essa maior suscetibilidade a erosões químicas e enzimáticas nos grânulos do tipo A, quando comparados aos do tipo B, é a presença de cascas protetoras (chamados blocos cristalinos) incorporadas estruturalmente ao redor dos grânulos tipo $B$, que são menos fortemente empacotados (OATES, 1997).

Existem vários fatores que afetam a estrutura cristalina do amido. A formação de cristais A é favorecida pelo menor comprimento médio de cadeia na amilopectina, pela alta temperatura de formação, pela alta concentração, pela presença de sal com alto número na série liotrófica (com exceção do $\mathrm{SO}_{4}^{-2}$ que induz o padrão B) ou pela presença de álcoois solúveis em água, ácidos graxos com maior número de carbonos e ácidos orgânicos (ELIASSON, 1996). Além disso, a transição entre os padrões A e B, passando pelo estado C, já foi observada em vários estudos, sugerindo que a estrutura A é a mais estável e pode seguir a seguinte ordem organizacional:

estrutura desorganizada (gelatinizada) $\rightarrow$ estrutura B $\rightarrow$ estrutura $\mathrm{C} \rightarrow$ estrutura A

Essa ordem sugere que os cristais B apresentam menor temperatura de derretimento $\left(77^{\circ} \mathrm{C}\right)$ quando comparado aos cristais A $\left(90^{\circ} \mathrm{C}\right)$ (ELIASSON, 2004). Além disso, o CL da amilopectina parece ser um fator determinante para a cristalinidade. Os amidos com padrão A apresentaram comprimentos de cadeia mais curtos $(C L \leq 19,7)$ do que amido do tipo B $(C L \geq 21,6)$, enquanto os amidos com CL entre 20,3 e 21,3 estiveram presentes em todos os tipos de amidos A, B e C. Por outro lado, cadeias muito longas parecem não afetar o polimorfismo (HIZUKURI et al., 1983).

\section{Propriedades físico-químicas}

Gelatinização

Quando o amido entra em contato com a água fria, os grânulos incham ligeiramente (10 a 20\%) devido à difusão e absorção de água nas regiões amorfas, mas esse processo é reversível pela secagem (WHO/FAO, 1998). No entanto, quando os grânulos são aquecidos em água, eles incham irreversivelmente num fenômeno denominado gelatinização, em que ocorre perda da organização estrutural (perda da birrefringência), com fusão dos cristais. Sabe-se que a gelatinização tem início no hilum e se expande rapidamente para a periferia, ocorrendo inicialmente nas regiões amorfas devido à fragilidade das ligações de hidrogênio nessas áreas, ao contrário do que ocorre nas regiões cristalinas (SINGH et al., 2003). À medida que os grânulos continuam se expandindo, ocorre a lixiviação da amilose da fase intergranular para a fase aquosa, resultando no aumento substancial das propriedades reológicas do sistema. O conjunto de mudanças que envolvem a ruptura da estrutura granular, o inchamento, a hidratação e a solubilização das moléculas de amido é definido como o fim da gelatinização (THARANATHAN, 2002).

Segundo SINGH et al. (2003), quando as moléculas de amido são aquecidas em excesso de água, a estrutura cristalina é rompida, e as moléculas de água formam pontes de hidrogênio entre a amilose e amilopectina, expondo seus grupos hidroxil, o que causa um aumento no inchamento e na solubilidade do grânulo. Esse poder de inchamento e solubilidade varia de acordo com a fonte do amido, fornecendo evidências da interação entre as cadeias de amido dentro dos domínios amorfos e cristalinos. A extensão destas interações é influenciada pela proporção amilose:amilopectina e pelas características dessas moléculas (distribuição e peso molecular, grau e comprimento de ramificações e conformação).

A gelatinização geralmente ocorre numa ampla faixa de temperatura característica para cada fonte de amido (ELIASSON, 1996; SINGH et al., 2003). Existem muitos fatores que afetam essa temperatura de gelatinização, sendo o principal deles a presença de água. Isso ocorre porque a água atua como agente plastificante nos cristais de amido, além de exercer efeito na condução de energia. Com isso, sua presença diminuirá a temperatura de transição vítrea, diminuindo conseqüentemente, a temperatura de fusão (desorganização) dos cristais (ELIASSON, 1996) e aumentando a suscetibilidade do amido à digestão pelas amilases do trato gastrointestinal (BJÖRCK et al., 1994).

As propriedades de inchamento e gelatinização são controladas, em parte, pela estrutura molecular da amilopectina (comprimento de cadeia, extensão de ramificação, peso molecular), composição do amido (proporção amilose:amilopectina e teor de fósforo) e arquitetura granular (proporção de regiões cristalinas e amorfas). Normalmente, altas temperaturas de transição têm sido associadas a altos graus de cristalinidade, os quais fornecem a estabilidade estrutural e tornam os grânulos mais resistentes à gelatinização (SINGH et al., 2003).

Atualmente, várias técnicas têm sido utilizadas para avaliar o comportamento dos grânulos frente à gelatinização, tais como: difração de raios X, 
dispersão de nêutrons de pequeno ângulo, microscopia com luz polarizada e, principalmente, calorimetria diferencial de varredura (DSC - Differential Scanning Calorimetry). Além disso, alguns equipamentos também avaliam a viscosidade de pastas de amido, como o viscoamilógrafo Brabender, o visco-analisador rápido (RVA - rapid visco-analyser) e os viscômetros de rotação, os quais dão uma idéia do comportamento do amido na gelatinização (SINGH et al., 2003; ELIASSON, 2004).

Devido à maior importância da amilopectina na cristalinidade do grânulo de amido, a presença da amilose reduz o ponto de fusão das regiões cristalinas e a energia necessária para o início da gelatinização, uma vez que mais energia é necessária para iniciar a fusão na ausência de regiões amorfas ricas em amilose. Essa correlação indica que amidos com maior conteúdo de amilose, por apresentarem mais regiões amorfas e menos regiões cristalinas, apresentam menores temperaturas de gelatinização.

Entretanto, estudos realizados com amido de arroz têm encontrado resultados contraditórios com relação à influência da amilose nas propriedades de gelatinização (VANDEPUTTE et al., 2003a; VANDEPUTTE et al., 2003b). Além disso, as entalpias de gelatinização (expressas no amido ou com base na amilopectina) não estão relacionadas ou diminuem com o conteúdo de amilose. Porém, uma correlação negativa entre o conteúdo de amilose e as temperaturas de pico $\left(\mathrm{T}_{\mathrm{p}}\right)$ e de conclusão $\left(\mathrm{T}_{\mathrm{c}}\right)$ da gelatinização é observada no caso de amidos cerosos e não-cerosos de várias fontes botânicas. Várias hipóteses foram sugeridas para explicar esses resultados conflitantes. Uma delas seria que a amilose pode existir sob a forma de complexos com lipídios (LAM) ou livre (FAM). A LAM é mais estável ao longo de toda a variação de temperatura de gelatinização do DSC, aumentando a $\mathrm{T}_{\mathrm{p}}$, enquanto a FAM amorfa diminuiria a T (MORRISON, 1995). Esses resultados sugerem que a FAM pode diminuir a temperatura de gelatinização de amidos normais. Além disso, esses resultados indicam que o aumento nas temperaturas de gelatinização no DSC com o conteúdo de amilose, para amidos de milho ricos em amilose, é possivelmente devido à cristalização conjunta da amilose com a amilopectina (VANDEPUTTE et al., 2003a).

\section{Retrogradação}

Quando é armazenado e resfriado, o amido gelatinizado pode sofrer um fenômeno denominado de retrogradação. Com o passar do tempo, as moléculas do amido vão perdendo energia e as ligações de hidrogênio tornam-se mais fortes, assim, as cadeias começam a reassociar-se num estado mais ordenado. Essa reassociação culmina com a formação de simples e duplas hélices, resultando no enredamento ou na formação de zonas de junção entre as moléculas, formando áreas cristalinas. Como a área cristalizada altera o índice de refração, o gel vai se tornando mais opaco à medida que a retrogradação se processa (ELIASSON, 1996). A amilose que foi exsudada dos grânulos inchados forma uma rede por meio da associação com cadeias que rodeiam os grânulos gelatinizados.

Como conseqüência, a viscosidade da pasta aumenta (viscosidade de setback), convertendo-se num sistema viscoelástico turvo ou em concentrações de amido suficientemente altas ( $>6 \% \mathrm{p} / \mathrm{p})$ num gel elástico opaco (LAJOLO \& MENEZES, 2006), em que, às vezes, ocorre precipitação de cristais insolúveis de amido levando à separação de fases. A forte interação das cadeias entre si promove a saída da água do sistema, sendo essa expulsão chamada de sinérese.

As características de retrogradação da amilose e amilopectina são cineticamente diferentes. A amilose retrograda mais rapidamente, tendo forte tendência a reassociar-se por meio da formação de pontes de hidrogênio com outras moléculas de amilose adjacentes, formando estruturas cristalinas de duplas hélices quando a solução esfria e se mantém por longo período de tempo. A amilose apresenta endoterma de fusão de $140^{\circ} \mathrm{C}$ a $180^{\circ} \mathrm{C}$, e a presença de ácidos graxos livres ou lipídios favorece a formação de complexos de inclusão. Por outro lado, a amilopectina retrograda numa taxa muito menor durante um longo período de tempo, e sua endoterma de fusão é menor, aproximadamente, $45^{\circ} \mathrm{C}$ a $60^{\circ} \mathrm{C}$ (WU \& SARKO, 1978; PARKER \& RING, 2001; THARANATHAN, 2002).

A retrogradação é um fenômeno complexo e varia de acordo com diversos fatores, como: temperatura e tempo de armazenamento, $\mathrm{pH}$, fonte de amido, presença de outros componentes (lipídios, eletrólitos e açúcares) e condições de processamento. Sabe-se, por exemplo, que a repetição de ciclos congelamento-descongelamento acelera drasticamente a retrogradação e a sinérese. Porém, a principal influência da retrogradação é observada na textura, na aceitabilidade e na digestibilidade dos alimentos que contém amido (ELIASSON, 1996; THARANATHAN, 2002; ELIASSON, 2004). Com isso, pode-se destacar a influência do processo de retrogradação no envelhecimento de pães e produtos de panificação, bem como na perda de água (sinérese) de algumas sobremesas que utilizam o amido como espessante. Quanto à digestibilidade, pode-se relacionar a retrogradação, principalmente da amilose, com menor 
disponibilidade de nutrientes às enzimas digestivas. Esse evento torna a digestão e a absorção, especialmente do amido, menor e/ou mais lenta, resultando em menor resposta glicêmica, situação desejável em diversos indivíduos, como aqueles com sobrepeso ou problemas de glicemia (BJÖRCK et al., 1994).

Alguns estudos têm mostrado que, como ocorre na gelatinização, algumas populações de cadeias de amilopectina podem favorecer (DP 12-22) ou inibir (DP 6-9; DP>25) a retrogradação da amilopectina devido à maior ou menor formação de duplas hélices durante a retrogradação (VANDEPUTTE \& DELCOUR, 2004). Porém, a influência exata da amilose na retrogradação ainda permanece obscura. É possível sugerir que a fração amilose apresenta um efeito sinérgico na retrogradação da amilopectina, atuando como um núcleo de recristalização no caso de baixos conteúdos de amilopectina (VANDEPUTTE et al., 2003c).

\section{CONSIDERAÇÕES FINAIS}

Vários estudos realizados nos últimos anos têm demonstrado que a fonte de amido pode influenciar de modo determinante diversos processos tecnológicos da indústria alimentícia, como a textura e a retenção de água de determinados alimentos, assim como processos metabólicos vitais da nutrição humana, como a resposta glicêmica ao alimento ingerido. Esses eventos estão intimamente relacionados a muitas características estruturais do amido, como teor de amilose, distribuição de comprimento das cadeias de amilopectina e cristalinidade no grânulo, sendo também associados a algumas etapas dos processos de gelatinização e retrogradação, como inchamento do grânulo, lixiviação de amilose e/ou amilopectina, perda da estrutura radial (birrefringência), supra-molecular (cristalinidade) e molecular e recristalização. Tais características pontos, abordadas na presente revisão, demonstram que, bem mais do que um simples componente energético, o amido deve ser estudado com base nas suas diferenciações químicas a fim de dirigir e otimizar sua aplicação tecnológica e nutricional.

\section{REFERÊNCIAS}

ASAOKA, M. et al. Characterization of endosperm starch from high-amylose mutants of rice (Oryzae sativa L.). Starch/ Stärke, v.38, p.114-121, 1986.

BAKER, A.A. et al. Internal structure of the starch granule revealed by AFM. Carbohydrate Research, v.330, p.249256, 2001. Disponível em: http://www.sciencedirect.com/
science?_ob=ArticleURL\&_udi=B6TFF-42DX1TT-1C\&_user= $687358 \&$ \&_doc $=1 \&$ \& $\mathrm{fmt}=\&$ \& orig $=$ search \&_sort $=\mathrm{d} \&$ view $=$ c \&_a c c t $=$ C $000037899 \&$ \& version $=1 \&$ \& url V e rsion $=0 \&$ _ us e ri d $=687358 \&$ m d $5=9$ c 73 127 fccf985e2249be367908d362f. Doi: 10.1016/S00086215(00)00275-5.

BJÖRCK, I. et al. Food properties affecting the digestion and absorption of carbohydrates. Americam Journal of Clinical Nutrition, v. 59(suppl), p.699S-705S, 1994.

BULÉON, A. et al. Starch granules: structure and biosynthesis. International Journal of Biological Macromolecules, v.23, p.85-112, 1998.

CURÁ, J.A. et al. Amylose is not strictly linear. Starch/ Stärke, v.47, n.6, p.207-209, 1995.

ELIASSON, A.C. Carbohydrates in food. New York: Marcel Dekker, 1996. 664p.

ELIASSON, A.C. Starch in food - Structure, function and applications. New York: Boca Raton, CRC, 2004. 605p.

HIZUKURI, S. et al. Measurement of the chain length of amylopectin and its relevance to the origin of crystalline polymorphism of starch granules. Biochimica et Biophysica Acta, v.760, p.188-191, 1983. Disponível em: http:// w w w s c i e $n$ c e d i $r$ e $t$. c o m/ science?_ob=ArticleURL\&_udi=B6T1W-47P8R4V$2 Y \& \_u s e r=687358 \&$ _rdoc $=1 \&$ fmt $=$ \&_orig $=$ search\&_sort $=$ d \&view $=$ \&\&_acct $=$ C000037899\&_version $=1 \&$ \&urlVersion $=0$ \&_userid $=6873$ $58 \&$ md5 $=320$ f9b8c3b981b81b557168543808563. Doi: 10.1016/0304-4165(83)90142-3.

HIZUKURI, S. Relationship between the distribution of the chain length of amylopectin and the crystalline structure of starch granules. Carbohydrate Research, v.141, p.295-305, 1985. Disponível em: http://www.sciencedirect.com/ science?_ob=ArticleURL\&_udi=B6TFF-42NJGB9-

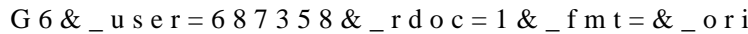

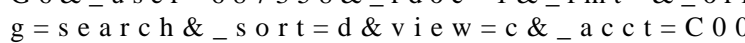
$0037899 \&$ \&ersion $=1 \&$ \&urlVers ion $=0 \&$ \&_userid $=687358 \&$ md5=9bb7db005955bf7b934bf3e81c367414. Doi: 10.1016/ S0008-6215(00)90461-0.

HIZUKURI, S. Polymodal distribution of the chain lengths of amylopectin and its significance. Carbohydrate Research, v.147, p.342-347, 1986.

IMBERTY, A. et al. Recent advances in knowledge of starch structure. Starch/Stärke, v.43, n.10, p.375-384, 1991.

KUAKPETOON, D.; WANG, Y. Internal structure and physicochemical properties of corn starches as revealed by chemical surface gelatinization. Carbohydrate Research, v.342, p.2253-2263, 2007. Disponível em: http:// w w w. s c i e n c e d i r e c t. c o m / science?_ob=ArticleURL\&_udi=B6TFF-4NYD8TP-

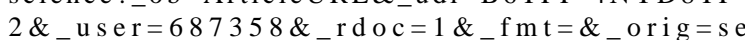
arch\&_sort $=\mathrm{d} \&$ view $=$ c\&_acct $=\mathrm{C} 000037899 \&$ \&version $=1 \&$ \&u rlVersion=0\&_userid=687358\&md5=f12851762c9f9a8c28a6a2ceab5164b9. Doi: $10.1016 /$ j.carres.2007.06.010.

LAJOLO, F.M.; MENEZES, E.W. Carbohidratos en alimentos regionales Iberoamericanos. São Paulo: Universidade de São Paulo, 2006. 648p. 
LAN, H. et al. Impact of annealing on the molecular structure and physicochemical properties of normal, waxy and high amylose bread wheat starches. Food Chemistry, v.111, p.663675, 2008. Disponível em: http://www.sciencedirect.com/ science?_ob=ArticleURL\&_udi=B6T6R-4SD6SPP $1 \&$ \& s e r $=687358 \&$ \& 68 o c $=1 \&$ \& $\mathrm{mt}=$ \&_orig $=$ search\&_sort $=\mathrm{d} \& \mathrm{view}=\mathrm{c} \&$ \&acct $=\mathrm{C} 00003789$ $9 \&$ _ v e r s i o n $=1 \&$ _ u r l Vers i o n $=0$ \& _ u s erid $=687358 \&$ md5 $=$ c6e81e69933a66ac901334daf8a9eed 1 . Doi: 10.1016/j.foodchem.2008.04.055.

LI, J.H. et al. Starch from hull-less barley: V. In vitro susceptibility of waxy, normal, and high-amylose starches towards hydrolysis by alpha-amylases and amyloglucosidases. Food Chemistry, v.84, p.621-632, 2004.

LINDEBOOM, N. et al. Analytical, biochemical and physicochemical aspects of starch granule size, with emphasis on small granule starches: a review. Starch/Stärke, v.56, p.8999, 2004. Disponível em: http://www3.interscience.wiley.com/ journal/107641838/abstract?CRETRY=1\&SRETRY=0. Doi: 10.1002/star.200300218.

MORRISON, W.R. Starch lipids and how they relate to starch granule structure and functionality. Cereal Food World, v.40, p.437-446, 1995.

OATES, C.G. Towards and understanding of starch granule structure and hydrolysis. Trends in Food Science \& Technology, v.8, p.375-382, 1997. Disponível em: http:// w w w. s c i e n c e d i r e c t. c o m / science?_ob=ArticleURL\&_udi=B6VHY-3WJDVT5$25 \& \_u s e r=687358 \& \_r d o c=18 \_f m t=\& \_o r i g=$ search\&_sort $=\mathrm{d} \&$ view $=\mathrm{C}$ $\&$ _acct $=$ C $000037899 \&$ \&_version=1\&_urlVersion $=$ 0\&_userid=687358\&md5 $=$ c487f3b961e27c3802dd02cb1b77e31a. Doi: 10.1016/S0924-2244(97)01090-X.

PARKER, R.; RING, S.G. Aspects of the physical chemistry of starch. Journal of Cereal Science, v.34, p.1-17, 2001. Disponível em: http://www.sciencedirect.com/ science?_ob=ArticleURL\&_udi=B6WHK-45BC2HVS\&_user $=687358 \& \_r d o c=1 \& \_\mathrm{fmt}=\mathbf{\&} \_$orig $=$search\&_sort $=\mathrm{d} \& \mathrm{view}=\mathrm{C}$ $\&$ _acct $=$ C $000037899 \&$ _version $=1 \&$ \&_urlVersion $=0$ \&_userid=687358\&md5=13470027af47ba147fce2e816343b21c. Doi: $10.1006 /$ jcrs.2000.0402.

SINGH, N. et al. Morphological, thermal and rheological properties of starches from different botanical sources. Food Chemistry, v.81, n.219-231, 2003. Disponível em: http:// w w w. s c i e n c e d i r e c t. c o m / science?_ob=ArticleURL\&_udi=B6T6R-47P91J1$8 \&$ \& us e r $=687358 \&_{\text {_rd o }}=1 \&_{\text {_ }} \mathrm{fm} \mathrm{t}=\&_{\text {_ o r i }}$

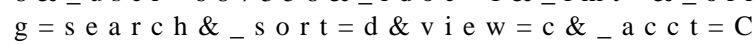
$000037899 \&$ \&ersion $=1 \&$ \&_urlVersion $=0 \&$ \&_userid $=6$ 87358\&md5=67bd8088b31cbd3db1b2c8039fb2d091. Doi: 10.1016/S0308-8146(02)00416-8.
STARK, J.R.; LYNN, A. Biochemistry of plant polysaccharides: starch granules large and small. Biochemical Society Transactions, v.20, p.7-12, 1992.

TESTER, R.F. et al. Starch - composition, fine structure and architecture. Journal of Cereal Science, v.39, p.151-165, 2004. Disponível em: http://www.sciencedirect.com/ science?_ob=ArticleURL\&_udi=B6WHK-4BNMH9W$4 \&$ _user $=687358 \&$ \&doc $=1 \&$ \&mt $=$ \&_orig $=$ search\&_sort $=\mathrm{d} \&$ view $=$ _acct $=$ C $000037899 \&$ \&_version $=1 \&$ _urlVersion $=0 \&$ _userid=687358\&md5=af13c384207409ca760f595fa217b8bd. Doi: $10.1016 /$ j.jcs.2003.12.001.

THARANATHAN, R.N. Food-derived carbohydrates - Structural complexity and functional diversity. Critical Reviews in Biotechnology, v.22, p.65-84, 2002. Disponível em: http:// www.informaworld.com/smpp/content $\sim \mathrm{db}=$ all? content $=10.1080$ / 07388550290789469 . Doi: 10.1080/07388550290789469.

VANDEPUTTE, G.E. et al. Rice starches. I. Structural aspects provide insight into crystallinity characteristics and gelatinisation behavior of granular starch. Journal of Cereal Science, v.38, p.43-52, 2003a.

VANDEPUTTE, G.E. et al. Rice starches. II. Structural aspects provide insight into swelling and pasting properties. Journal of Cereal Science, v.38, p.53-59, 2003b. Disponível em: h t t p : / / w w w. s c i e n c e d i r e c t. c o m / science?_ob=ArticleURL\&_udi=B6WHK-48BKSYR$2 \&$ \&user $=687358 \&$ \&_rdoc $=1 \&$ \& fmt $=\&_{-}$orig $=$searc $\mathrm{h} \&$ _sort $=$ d\&view $=$ c \&_acct $=\mathrm{C} 000037899 \&$ \&_version $=1$

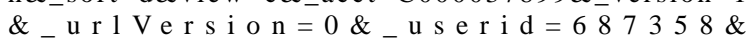
md5 $=317283 b f 5 a 07688 c b 28661815 a 73 b 262$. Doi: $10.1016 /$ S0733-5210(02)00141-8.

VANDEPUTTE, G.E. et al. Rice starches. III. Structural aspects provide insight in amylopectin retrogradation properties and gel texture. Journal of Cereal Science, v.38, p.61-68, 2003c. Disponível em: http://www.sciencedirect.com/ science?_ob=ArticleURL\&_udi=B6WHK-48BKSYR$4 \&$ _user $=687358 \& \_r d o c=1 \& \_$fmt $=\&$ \&orig $=$ search\&_sort $=\mathrm{d} \&$ vie $\mathrm{w}=\mathrm{c} \&$ \&acct $=\mathrm{C} 000037899 \&$ \&ersion $=1 \&$ \&_urlVersion $=0$ \&_userid $=6$ 87358\&md5=aa31153f50c97852687ac79431f1e392. Doi: 10.1016/S0733-5210(02)00142-X.

VANDEPUTTE, G.E.; DELCOUR, J.A. From sucrose to starch granule to starch physical behavior: a focus on rice starch. Carbohydrate Polymers, v.58, p.245-266, 2004.

WANG, L.Z.; WHITE, P.J. Structure and properties of amylose, amylopectin, and intermediate materials of oat starches. Cereal Chemistry, v.71, p.263-271, 1994.

WHO/FAO. Carbohydrates in human nutrition. Rome: FAO, 1998, (FAO food and nutrition paper no. 66).

WU, H.C.H.; SARKO, A. The double-helical molecular structure of crystalline A-amylose. Carbohydrate Research, v.61, p.27-40, 1978 . 